\title{
Teeth and benign oesophageal stricture
}

\author{
D G MAXTON, C C AINLEY, S L GRAINGER, R W MORRIS, AND \\ R P H THOMPSON
}

From the Gastrointestinal Laboratory and Department of Community Medicine, The Rayne Institute, St Thomas' Hospital, London

SUMMARY In patients undergoing upper gastrointestinal endoscopy, benign oesophageal strictures were significantly more frequent $(p<0.01)$ in those with severe tooth loss than in controls of the same age. This may be because of (i) edentulous patients eating less solid and more liquid food, which would otherwise dilate the lower oesophagus, or (ii) poor salivary flow leading to both tooth loss and impaired neutralisation of refluxed gastric acid, or (iii) malnutrition. No association was found, however, between either oesophagitis or hiatus hernia and dentition.

Benign oesophageal stricture is thought to be a complication of prolonged reflux oesophagitis, but few patients with oesophagitis or hiatus hernia develop strictures and often there is little history of heartburn. ${ }^{1}$ Other factors may therefore be important in their aetiology.

We noted that patients requiring endoscopic dilatation for benign oesophageal strictures were often partially or completely edentulous, and therefore sought an association between lack of teeth and the presence of such strictures.

\section{Methods}

\section{PATIENTS}

All patients undergoing endoscopy at St Thomas' Hospital over a two year period (1982-84) were studied. The state of dentition and presence of dentures were noted at the time of endoscopy.

Dental state was defined as:- Group I: all natural teeth, or most natural teeth with only partial dentures. Group II: edentulous, or few natural teeth - that is, complete dentures either upper or lower jaw.

Three thousand, six hundred and sixty four patients underwent upper gastrointestinal endoscopy during the study period. Four diagnostic groups were assessed:- 103 who required dilatation for benign oesophageal stricture on at least one occasion, 1126 patients with normal endoscopic

Address for correspondence: Dr R P H Thompson. The Rayne Institute, St Thomas' Hospital, London SE1 7EH.

Received for publication 2 May 1986. appearances, 530 with macroscopic evidence of oesophagitis and 285 with an endoscopically demonstrable hiatus hernia. One hundred and thirty nine patients had both oesophagitis and hiatus hernia and were included in both groups.

Analysis was done by comparing each of the three disease groups separately with the normal endoscopy group. The patients were subdivided into age bands of five years from 20 to 94 years to produce groups matched by age to within five years. In each disease group the observed number of patients with and without teeth in each age band was determined and compared in a $2 \times 2$ contingency table with the same data from the age-matched normal endoscopy group. Assuming the null hypothesis of no association between dentition and each disease, the expected numbers of patients at each age with and without teeth in both normal and disease groups were then computed. The observed and expected numbers were summed separately, excluding the age bands in which there were no patients, to create an overall pooled contingency table ${ }^{2}$ for each disease group, and a Pearson $\chi^{2}$ statistic was then calculated.

The association between disease group and loss of teeth was thus evaluated, stratified for age and thus avoiding associations due to age alone. No assessment was made of severity of oesophagitis or size of hiatus hernia, nor whether dentures were usually worn for eating.

\section{Results}

Observed and expected numbers of oesophageal 
strictures are shown in Table 1 . For clarity only 10 year age bands, produced by combining two five year bands, are given. Thus, assuming no relationship between dental state and benign oesophageal stricture, 74.2 of the 103 stricture patients would have been expected to have poor dentition but, in fact, 87 patients did so. Conversely, 28.8 patients with a benign oesophageal stricture would have been expected to possess good dentition, but only 16 did so. Therefore significantly more patients with a benign oesophageal stricture had poor dentition and significantly fewer had good dentition $(p<0.01)$ than would be expected if no association existed between stricture and dental state.
Total observed and expected numbers of patients with good (Group I) and poor (Group II) dentition with either oesophagitis or hiatus hernia are given in Table 2. In both these disease groups, and in contrast with benign oesophageal stricture, close agreement is shown between the observed number in each dental group and the number expected. Thus there is no significant association between either oesophagitis or hiatus hernia and dentition.

\section{Discussion}

After correction for age there was a strong association between the absence of teeth and benign oesophageal stricture, but the dental state of

Table 1 Observed and expected number of patients by age with and without teeth: normal and benign oesophageal strictures

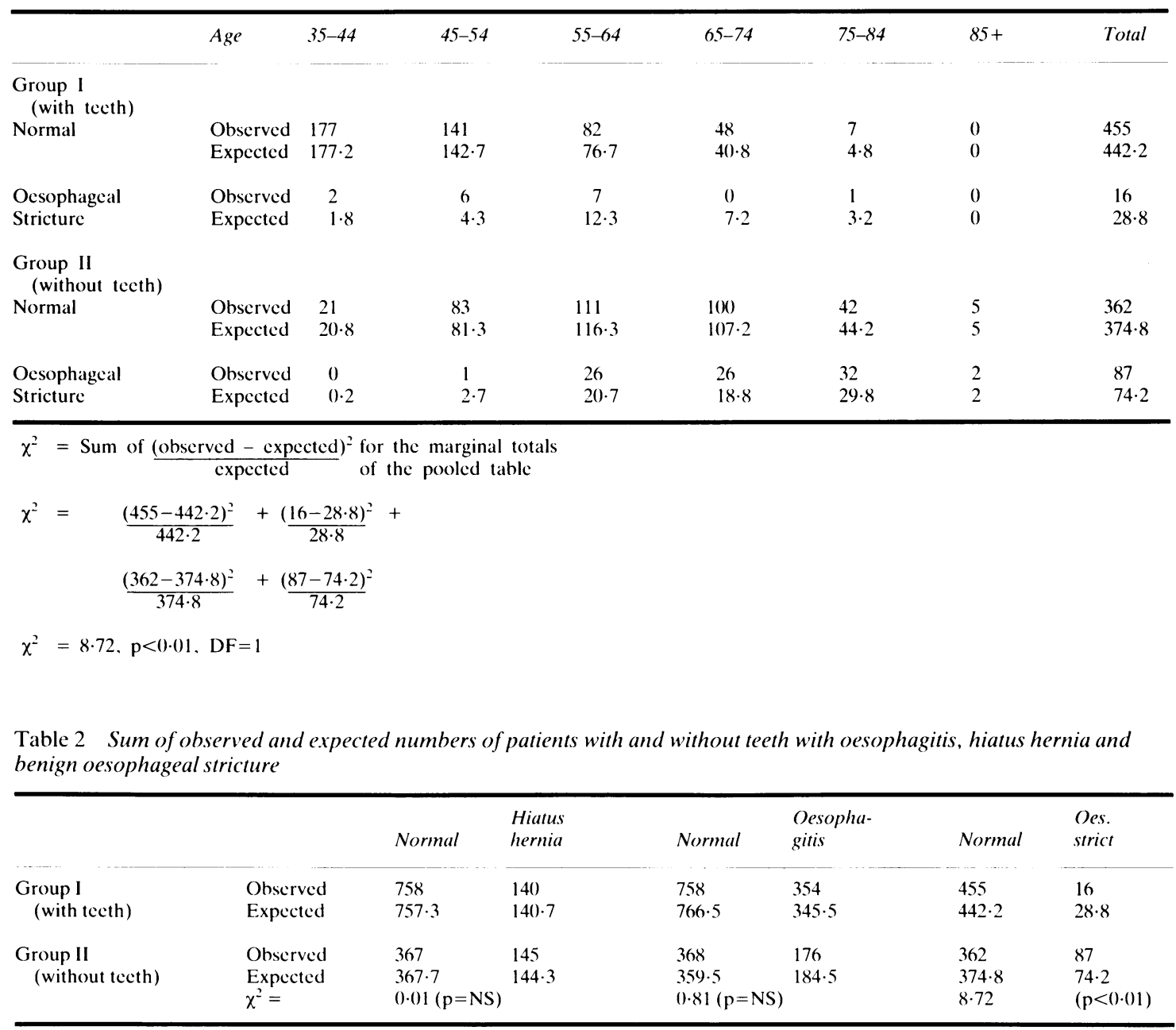


patients with oesophagitis and hiatus hernia did not differ from that of patients with normal endoscopic examinations.

Patients with a normal endoscopy were taken as the control group. Although they may differ from the general population, this group have endoscopically confirmed normal upper gastrointestinal tracts, which, given the high prevalence of gastrointestinal disease, may not be so with control groups that have not been investigated, such as patients seen in general practice.

The simplest explanation of our findings is that poor dentures reduce masticatory ability, which predisposes to development of oesophageal stricture. We did not assess masticatory performance, but edentulous patients eat less solid food, ${ }^{3-5}$ with therefore fewer food boluses to dilate the oesophagus during swallowing. In addition, however, the total calorie intake of people without teeth is also lower, with more carbohydrate and less protein. ${ }^{6}$ Underlying malnutrition might therefore by itself predispose to stricture formation. Alternatively, as saliva is important in neutralising gastric acid refluxing into the oesophagus, ${ }^{7}$ and impaired salivary function predisposes to tooth loss, ${ }^{8}$ poor salivary flow might result both in more prolonged acid contact with the lower oesophagus and in poor dentition.

Other authors have noted the discrepancy between severe symptomatic oesophagitis without stricture and the relatively symptom free patient with stricture formation, at least until dysphagia develops. ${ }^{19}$ In a recent study, only $60 \%$ of patients with stricture gave a history of dyspepsia. ${ }^{9}$ Further predisposing causes for strictures have therefore been sought, such as drugs, particularly nonsteroidal anti-inflammatory agents ${ }^{910}$ and potassium compounds. ${ }^{11}$

In conclusion, the association of benign oesophageal stricture with lack of teeth suggests that a local factor, possibly fewer and softer food boluses, may be important in the development of the stricture. A general effect of tooth loss, such as poor nutrition, however, or another condition predisposing to both stricture formation and dental disease, may be causal. At present we suggest that patients with benign oesophageal stricture are urged to use their dentures to eat solid food, and thereby perhaps reduce the need for repeated endoscopic dilatations.

We are grateful to the nursing staff of the Gastrointestinal Laboratory, the other endoscopists who recorded the data, and the Special Trustees of St Thomas' Hospital. This work was presented at the meeting of the British Society of Gastroenterology, April 1984.

\section{References}

1 Bennett JR. Oesophagitis. In: Bouchier IAD, Allan RN, Hodgson HJF, Keighley MRB, eds. Textbook of gastroenterology. London: Balliere Tindall, 1984: $40-51$.

2 Armitage P. Statistical methods in medical research. Oxford: Blackwell, 1971: 369-74.

3 Geissler CA, Bates JF. Nutritional effects of tooth loss. Am J Clin Nutr 1984; 39: 478-89.

4 Heath MR. Dietary selection by elderly persons related to dental state. $B$ Dent $J 1972 ; 132$ : 145-8.

5 Editorial: Age, masticatory ability and swallowing. Nutr Rev 1983; 41: 344-6.

6 Barone JV. Nutrition of edentulous patients. J Pros Dent 1965; 15: 804-9.

7 Helm JF, Dodds WJ, Pelc LR, Palmer DW, Hogan WJ, Teeter BC. Effect of esophageal emptying and saliva on clearance of acid from the oesophagus. $N$ Engl J Med 1984; 310: 284-8.

8 Afonsky D. Saliva and its relation to oral health. Alabama: Univ of Alabama Press, 1961: 21-5.

9 Wilkins WE, Ridley MG, Pozniak AL. Benign stricture of the oesophagus: role of non-steroidal antiinflammatory drugs. Gut 1984; 25: 478-80.

10 Heller SR, Fellows IW, Ogilvie AL, Atkinson M. Nonsteroidal anti-inflammatory drugs and benign oesophageal stricture. Br Med J 1982; 285: 167-8.

11 Howie AD, Strachan RW. Slow release potassium chloride treatment. Br Med J 1975; 2: 176. 